\title{
Blended cement containing high volume ground dune sand and ground granulated blast furnace slag for autoclave concrete industry
}

\begin{abstract}
This paper presents the results of using ground dune sand (GDS) and ground granulated blast furnace slag (slag) as high volume cement replacement materials. In this study, plain and four blended mixtures were fabricated and cured under normal and autoclave conditions. For the blended mixtures, $40 \%$ GDS by weight of the total binder materials and different percentages of slag $(15 \%, 30 \%$ and $45 \%)$ were incorporated as partial cement replacement materials. The effect of curing conditions (normal and autoclave) on the compressive strength of prepared mixtures was studied. The results showed that, for the autoclave cured mixture, up to $85 \%$ of cement can be replaced by GDS and slag without significant drop in the compressive strength. Microstructure analyses using scanning electron microscope (SEM) and X-ray diffraction analysis (XRD) were carried out to examine the microscale changes of the hydrated mixtures. The SEM revealed the formation of thin plate-like calcium silicate hydrate and compacted microstructure of autoclave cured mixture. XRD showed the elimination of calcium hydroxide and existence of residual crystalline silica of all blended mixtures.
\end{abstract}

Keyword: Ground Dune sand; Slag; Autoclave curing; Microstructure analysis; SEM; XRD 